\title{
Niet zulke jazzy impressies uit Japan
}

\author{
Lucas Noyon \& Beatrijs Jue-Volker
}

\section{Inleiding}

Voor het vakantie-themanummer van PROCES hebben wij een bijdrage geschreven die is gebaseerd op een studiereis naar Tokio in april 2017. Over deze reis kunnen wij veel schrijven, over wat ons daar aan het strafrecht is opgevallen in het bijzonder. Wij hebben echter niet de illusie in de korte tijd die ons daar gegeven was experts te zijn geworden op het gebied van het Japanse strafrecht, noch voelen we ons zeker genoeg op het terrein van de antropologie om vanuit een sociaalwetenschappelijke hoek sterke uitspraken te doen over hoe het er in Japan aan toegaat. Met deze bijdrage pretenderen we dan ook niet meer dan te vertellen wat ons is opgevallen, waarbij we ons richten op die aspecten waarvan wij denken dat ze voor mensen die net als wij toch vooral georiënteerd zijn op het Nederlands strafrecht, interessant zijn om te lezen.

Hiertoe schetsen we in het navolgende eerst met breed penseel de grondtrekken van het Japanse strafrecht. Een stelsel dat naar de letter lijkt op het onze, maar in de uitwerking toch sterk blijkt te verschillen. Daarna staan we kort stil bij enkele recente hervormingen. Japan heeft, net als wij en net als alle westerse landen, te maken met een verhit maatschappelijk debat en punitief populisme. De oplossing hiervoor lijkt het vooral te hebben gezocht in zaken die ook ons niet onbekend zijn, waaronder democratisering van het straf(proces)recht en emancipatie van het slachtoffer. Zoals we zullen zien, zijn in Japan echter veel radicalere keuzes gemaakt dan hier - en alleen al daarom biedt het voor de Nederlandse rechtspraktijk zowel letterlijk als figuurlijk een aardig vergezicht. Tot slot besteden we nog aandacht aan het wat ons betreft meest aangrijpende onderdeel van onze studiereis, een bezoek aan de Fuchu-gevangenis en een kennismaking met een Japanse notie van disciplinering aldaar.

Onze schets van het Japanse strafrecht is behalve op een bescheiden hoeveelheid inleidende literatuur hoofdzakelijk gebaseerd op lezingen van en discussies met deskundigen ter plekke, in het bijzonder Miki Hirano, hoogleraar Straf(proces)recht aan de Kagawa Universiteit, Tatsuya Ota, hoogleraar aan de Keio Universiteit, en Andrea Ortolani, universitair docent aan laatstgenoemde universiteit. Voor wat betreft onze indruk van de Japanse strafrechtadvocatuur leunen wij tot op grote hoogte op een bezoek aan de Japanese Bar Association en Nakamura International Criminal Defense. Om die reden permitteren wij het ons om iets minder strikt te zijn in onze literatuurverwijzingen, al doen wij de lezer hier en daar enkele suggesties om verder te lezen aan de hand. 


\section{Enkele grondtrekken van het Japans strafrecht}

Het Japanse strafrecht is net als het onze op een hoofdzakelijk Franse leest geschoeid, ${ }^{1}$ al doet het door een aantal recente hervormingen, waaronder de invoering van een quasi-jurystelsel, wat meer accusatoir aan. Voor de Nederlandse strafrechtjurist is onder meer de sterke positie van het Openbaar Ministerie $(\mathrm{OM})$ herkenbaar. Dit uit zich mede in het Japanse opportuniteitsbeginsel en een vervolgingsmonopolie. Het negatief geformuleerde opportuniteitsbeginse ${ }^{2}$ laat het OM de ruimte om zaken niet te vervolgen, een bevoegdheid waarvan het Japanse OM veel vaker gebruikmaakt dan het Nederlandse. Dit leidt er onder meer toe dat in die zaken waarin wel tot dagvaarding wordt overgegaan, het veroordelingspercentage hoger ligt dan 99,9\% (!). Het vervolgingsmonopolie van het Japanse OM lijkt bovendien nog minder ruimte te laten voor exogene aansturing dan in Nederland. Allereerst omdat anders dan bij ons - denk aan de politiestrafbeschikking en de bestuurlijke strafbeschikking - de Japanse wetgever geen uitzonderingen op dit monopolie heeft willen maken. In de tweede plaats omdat Japan niet een rechtsfiguur kent die vergelijkbaar is met onze artikel 12-procedure. Hierdoor waren, tot voor kort, sepotbeslissingen onaantastbaar. Sinds enkele jaren bestaat echter wel een andere vorm van toetsing, waarbij niet de direct belanghebbende maar een lekenjury de sepotbeslissingen reviseert. Daar komen wij in de volgende paragraaf nog op terug.

Deze inrichting van het strafrechtelijk speelveld heeft een veelheid aan consequenties, waaronder een beperkt tegensprekelijk karakter, een verschuiving van zwaartepunt naar het vooronderzoek en - hiermee corresponderend - een afnemende relevantie van het eindonderzoek, stigmatisering van verdachten reeds voordat sprake is van een veroordeling, en een gemarginaliseerde rol voor de verdediging na het nemen van de vervolgingsbeslissing. Minder gemakkelijk te verbinden aan de sterke rol van het OM lijkt dat het Japanse strafproces veel sterker dan het onze georiënteerd lijkt op het slachtoffer in plaats van op het algemeen belang. Wij gaan hierna op enkele in het oog springende eigenschappen in.

Een belangrijk kenmerk van het Japanse strafproces lijkt het zeer beperkt tegensprekelijke karakter. Het bijzonder hoge veroordelingspercentage komt enerzijds doordat slechts tot vervolging wordt overgegaan indien het voorhanden bewijs overstelpend is, anderzijds doordat zeer veel zaken de rechter niet bereiken omdat op grond van opportuniteitsafwegingen hiervan wordt afgezien. Veel factoren spelen hierbij een rol, waarvan een belangrijke is dat cultureel een groot gewicht wordt toegekend aan excuses en verzoening. Verdachten kunnen in veel gevallen een strafzaak afwenden indien zij nadrukkelijk verantwoordelijkheid

1 Zie hierover E. Herber, 'Juryleden, slachtoffers en het OM Hervorming en continuïteit in het Japanse strafproces', AA 2016, p. 735-744.

2 'Het is mogelijk om niet te vervolgen, wanneer vervolging als niet noodzakelijk wordt beschouwd op basis van het karakter, de leeftijd en omstandigheden van de dader, de ernst van en omstandigheden rond het delict en de omstandigheden na het delict.' 
nemen voor hun daad. Maar als het toch tot een dagvaarding komt, lijkt hun lot grotendeels al bezegeld.

Mede doordat slechts tot vervolging wordt overgegaan op het moment dat het bewijs overstelpend is, lijkt in de zaken die de rechter wel bereiken vooral te worden geconcentreerd op verzachtende omstandigheden en de strafmaat. Ook hier lijkt de verdachte vooral te winnen te hebben bij een onderdanige, schuldbewuste proceshouding. Het is wellicht mede door deze inrichting dat in de literatuur wel is gesteld dat het Japanse strafproces zich niet goed laat karakteriseren op de dimensies 'crime control' en 'due process', maar dat veeleer sprake is van een 'familiemodel'. ${ }^{3}$ Als dit zo is, is het in elk geval een familie in de traditionele betekenis van het woord. Van een 'onderhandelingshuishouding', om met Abram de Swaan te spreken, lijkt in elk geval niet echt sprake. ${ }^{4}$

Een volgende factor die bijdraagt aan het weinig tegensprekelijke karakter van het Japanse strafproces lijkt terug te voeren op de opleiding en de taakopvatting van de verschillende procesdeelnemers. Niet alleen rechters en officieren van justitie, maar ook advocaten volgen grotendeels dezelfde opleiding. Advocaten die wij daarnaar vroegen, spraken ook over het strafproces in termen van een 'gezamenlijk project' waar door de drie te onderscheiden deelnemers aan werd gewerkt. Misschien waren deze woorden soms wat ongelukkig gekozen, wellicht speelde gebrekkige taalvaardigheid een rol; wij willen niet betwisten dat de Japanse strafadvocaat in de eerste plaats het belang van zijn cliënt voor ogen heeft. Maar als wij het advocatenethos goed proefden, lijkt er toch sprake van een wezenlijk andere, meer coöperatieve houding dan wij hier gewend zijn.

Een ander kenmerk van de Japanse inrichting van het strafproces is dat het zwaartepunt nadrukkelijk in het vooronderzoek ligt, nog veel sterker dan bij ons al het geval is. Voor de verdachte lijkt hier ook het meest te halen; de kans dat door een welwillende en berouwvolle houding een (voorwaardelijk) beleidssepot kan worden afgedwongen is immers aanzienlijk. Hiermee hangt samen dat indien eenmaal tot vervolging wordt besloten, verdachten in de publieke opinie al als zijnde schuldig worden gebrandmerkt. Ook het publiek weet immers dat in nagenoeg alle gevallen een bewezenverklaring volgt. ${ }^{5}$ Het lijkt soms alsof er sprake is van een cirkel waar men maar moeilijk uit kan breken. Het maatschappelijk stigma dat de start van vervolging met zich brengt, lijkt ertoe te leiden dat extra terughoudend met die beslissing wordt omgesprongen, hetgeen op langere termijn dan weer het vooroordeel bestendigt dat de aanvang van vervolging feitelijk neerkomt op een schuldvaststelling.

3 Aldus ook Herber 2016. Vergelijk H.L. Packer, The limits of the criminal sanction, Stanford: Stanford University Press 1968.

4 Vergelijk A. de Swaan, De mens is de mens een zorg, Amsterdam: Amsterdam University Press 2011.

5 Men zegt dat (maar zou het anders zijn dan hier?) de berechting van strafbare feiten, zeker sinds de introductie van het jurystelsel, een publiek schouwspel is geworden die veel media-aandacht trekt. Ook is het gebruikelijk dat verdachten met naam en toenaam worden genoemd en getoond. Vergelijk Herber 2016. 
Het laatste kenmerk dat ons is opgevallen, is dat het Japanse strafrecht veel meer dan het onze georiënteerd is op het slachtoffer. De legitimatie voor strafvervolging lijkt veeleer te worden gezocht in de inbreuk op subjectieve rechten in plaats van in de meer abstracte deuk in de rechtsorde. Ten dele zit dit al ingebakken in de hiervoor besproken rol van excuses en verzoening bij sepotbeslissingen. Deze grondtoon is daarnaast ook herkenbaar in de positie van het slachtoffer. Een in Nederland niet onbekend thema, zij het dat dit in Japan veel verder is doorgevoerd dan hier. Zo hebben slachtoffers in Japan een plek in de zittingszaal direct naast de officier van justitie, hebben zij het recht een strafeis uit te spreken en het recht om de verdachte ter zitting te ondervragen. Dit zijn slechts recente ontwikkelingen, die naar het ons scheen nog enigszins tot onwennigheid aanleiding geven in de rechtspraktijk. Veel langer terug gaat echter de ruime categorie aan delicten die alleen op klacht vervolgbaar zijn. Hieronder vallen bijvoorbeeld alle zedendelicten.

\section{Recente hervormingen}

Wie kennismaakt met de conflictmijdende en hiërarchierespecterende inborst van de Japanner, zou wellicht niet verwachten - zeker niet na een blik geworpen te hebben op de indrukwekkend lage misdaadcijfers, de beperkte omvang van de gevangenispopulatie en de strengheid van het detentieregime - dat ook in Japan een verhit publiek debat over misdaad en straf is ontstaan. De politieke denkrichting die wel wordt aangeduid met de term 'punitief populisme', ${ }^{6}$ lijkt echter ook in Japan vaste voet aan de grond te hebben gekregen. Het maatschappelijke sentiment dat de strafrechtspraak te ver zou afstaan van de 'gewone man' en onvoldoende streng zou straffen, heeft aanleiding gegeven tot enkele hervormingen. Hiervoor stipten we al kort de introductie van het 'quasi-jurystelsel' aan, alsmede de toetsing door lekenjury's van sepotbeslissingen en maatregelen die de positie van het slachtoffer versterken. Op de eerste twee hiervan gaan we in deze paragraaf nog iets dieper in.

Overigens moet gezegd dat het ons niet uitgesloten lijkt dat deze hervormingen ook ten dele zijn ingegeven door een uitbreiding van de Angelsaksische invloedssfeer. Japan heeft zijn blik tegenwoordig nu eenmaal meer op de Verenigde Staten gericht dan op Europa en dit lijkt ook zijn weerslag te vinden in de inrichting van het strafrecht. Toch wordt desgevraagd door deskundigen in Japan de oorzaak van de hervormingen primair gezocht in de maatschappelijke wens hiertoe. Alleen al daarom - punitief populisme is immers ook in Nederland geen onbekend fenomeen, evenals de als ware vanzelfsprekend gebrachte opvatting dat een werkelijk legitiem strafrecht zou moeten democratiseren en verstrengen - biedt het een aardig referentiepunt voor de Nederlandse strafrechtspraktijk.

6 De term 'punitief populisme' is gemunt door Bottoms: A. Bottoms, 'The philosophy and politics of punishment and sentencing', in: C. Clarkson \& R. Morgan, The politics of sentencing reform, Oxford: Clarendon press 1995, p. 17-50, in het bijzonder p. 40. Zie hierover ook bijvoorbeeld J. Pratt, Penal populism, Londen: Routledge 2007. 
De introductie van het 'Saiban-In' quasi-jurystelsel is een van de meest opmerkelijke veranderingen die het Japanse strafrecht heeft ondergaan. De jury's oordelen in strafzaken waarin ernstige misdrijven zoals moord, doodslag of brandstichting ten laste zijn gelegd, zowel over de schuld als over de straf. Andere beslissingen zijn voorbehouden aan professionele rechters. ${ }^{7}$ Ook vanuit het perspectief van de invloed van punitief populisme is dit opmerkelijk: alhoewel in veel landen de burger is toegelaten als adviseur in allerlei strafvorderlijke kwesties, ${ }^{8}$ denk hierbij ook aan de 'burgerfora' die het Openbaar Ministerie in Nederland enige tijd heeft georganiseerd, ${ }^{9}$ is voor zover ons bekend nergens anders daadwerkelijke beslissingsmacht door professionals overgedragen aan burgers. Het voorvoegsel 'quasi' laat zich overigens verklaren doordat in de jury's niet uitsluitend burgers zitten, maar hierin ook - in minderheid - professionele rechters plaatsnemen. ${ }^{10}$

De invoering van jury's lag niet direct voor de hand, omdat voor de invoering uit enquêtes bleek dat de meerderheid van de Japanners de invoering van juryrechtspraak afkeurde en men het bovendien in groten getale niet zag zitten zelf ooit plaats te moeten nemen in een jury. Dit is overigens niet anders in Nederland; burgers hier zijn traditioneel sterk gekant tegen lekenrechtspraak. ${ }^{11}$ Inmiddels lijkt het beeld wat gekanteld: een meerderheid van de Japanners steunt inmiddels de quasi-juryrechtspraak. ${ }^{12}$ Voor wat betreft de eigen participatie concentreert het politieke debat zich tegenwoordig op de vraag of burgers zich zouden moeten kunnen verschonen van zittingname in een jury op grond van gewetensbezwaren. Dit lijkt, gezien het feit dat jury's bij gewone meerderheid beslissen, ${ }^{13}$ het Japanse detentieklimaat behoorlijk streng is en ook de doodstraf tot het instrumentarium behoort, geen zinledige discussie.

Een tweede hervorming die we hier willen noemen is de introductie van burgerjury's die sepotbeslissingen beoordelen, het Prosecution Inquest System. Dat hier behoefte aan was, kan, zeker gezien het feit dat men onbekend is met een rechtsingang voor de direct belanghebbende (vgl. art. 12 Wetboek van Strafvordering), wel worden begrepen. Opnieuw samenhangend met het hoge veroordelingspercentage schijnt een incidentele vrijspraak sterk op de behandelend officier van justitie af te stralen. Mede om de eigen carrière te bewaken zouden zij slechts in uitzonderlijk sterke zaken dagvaarden. Dat dit af en toe tot onbevredigende sepots kan leiden, laat zich raden.

$7 \quad$ Herber 2016.

8 Zie hierover bijvoorbeeld A. Freiberg \& K. Gelb, Penal populism, sentencing councils and sentencing policy, Collumpton: Willan 2008.

9 Zie K. Lünnemann, 'Burgerpanels en het strafvorderingsbeleid van het OM: het experiment in 2007', Trema straftoemetingsbulletin 2013, p. 18-22.

10 De standaard quasi-jury bestaat uit zes leken en drie professionele rechters, maar dit kan onder omstandigheden anders zijn.

11 M. Koomen, Lekenparticipatie in de strafrechtspraak. Het beeld van de Nederlandse bevolking, Amsterdam: WODC/TNS-NIPO.

12 Herber 2016.

13 Aangetekend moet worden dat ten minste één professionele rechter ook tot die meerderheid moet behoren. 
De oplossing die men heeft gevonden, bestaat uit een gecompliceerd en naar het zich laat aanzien tijdsintensief mechanisme waarbij een lekenjury alle formele sepots onderzoekt. Indien deze tot het oordeel komt dat vervolging toch aangewezen is, wordt de zaak teruggestuurd naar het OM. De officier wordt zo de gelegenheid geboden op zijn schreden terug te keren en alsnog te vervolgen. Indien hij persisteert, is het laatste woord opnieuw aan de jury. Wanneer ook die blijft bij het aanvankelijke oordeel, wordt een advocaat aangesteld als een private aanklager. Deze krijgt dan alle bevoegdheden die ook toekomen aan een officier van justitie, waaronder dus ook het geven van leiding aan het opsporingsonderzoek. De figuur van private aanklager bestaat buiten deze rechtsingang niet, en de vraag lijkt ons gerechtvaardigd of deze zo uitvoerig opgetuigde procedure nou een succes kan worden genoemd.

\section{De Fuchu-gevangenis}

Aan het slot van deze bijdrage willen we nog kort stilstaan bij een meer persoonlijke ervaring. Onderdeel van de studiereis was een bezoek aan de Fuchu-gevangenis, een volgens de medewerkers van de Nederlandse ambassade relatief moderne en grote instelling.

Over de detentieomstandigheden kunnen we kort zijn: de cellen waren niet groot en de gedachte dat gedetineerden daar in de winter in de vrieskou zitten en in de zomer in 40 graden het hoofd koel moeten houden, stemt niet vrolijk. De werkelijke wreedheid school echter in de structuur van het regime, die door het verbieden van elementair menselijk gedrag en het programmeren van mechanische discipline een bizar, kil en gedehumaniseerd schouwspel produceert.

Met name de sterk gemilitariseerde organisatiestructuur, hetgeen zich onder meer uitte in alomtegenwoordige uniformen, barse salueringen en marcherende gedetineerden, gaf het geheel een rauw en op een surrealistische wijze van menselijkheid ontdane aanblik. De dwangarbeid, twee keer vier uur per dag, greep ons bij de keel vanwege de overrompelende eenvoud van het werk en het vooruitzicht dat veel gedetineerden dit tot aan hun dood zouden moeten doen, maar vooral vanwege de wijze waarop dit ten uitvoer werd gelegd: een verbod om te praten en een verbod elkaar, de commandant ter plaatse of - in ons geval - het toevallige bezoek ook maar aan te kijken. Normale vormen van alledaagse menselijke interactie zijn dus verboden. Het prentte ons een herinnering in die we moeilijk anders kunnen noemen dan fordistische tortuur, zeker als daarbij bedacht wordt dat de straf op toch praten of elkaar een blik toewerpen niet alleen kan bestaan uit een dag doorbrengen in de isoleercel, maar ook uit de opdracht die dag in dezelfde houding te blijven zitten. ${ }^{14}$

14 Door de gebrekkige communicatie met de gevangenisdirecteur kunnen we niet uitsluiten dat wij hem verkeerd begrepen als we veronderstellen dat met 'een dag' daadwerkelijk 24 uur werd bedoeld. Al is wellicht de wens hier de vader van de gedachte. 


\section{Afsluiting}

Aan het eind van zo'n reis dringt zich uiteraard de vraag op hoe de ervaringen daar moeten worden gewaardeerd en in hoeverre wij in Nederland iets zouden kunnen leren van de Japanse praktijk. Het valt ons niet mee die vraag te beantwoorden. Japanse deskundigen lijken zich, wanneer ze het systeem aan ons uitleggen, vooral te generen voor het feit dat de verhoorsbijstand voor een raadsman in Japan niet is geregeld. Ook voelt men zich licht opgelaten over recente uitbreidingen van toezichtsmodaliteiten na ommekomst van de detentie, die zich redelijk goed laten vergelijken met de - eveneens van recente datum - mogelijkheden voor langdurig toezicht in Nederland. Beide 'tekortkomingen' zijn voor ons dus wel herkenbaar, maar zijn nou niet de eigenschappen die ons het meest zullen bijblijven. Al kan dit natuurlijk ook komen doordat wij kampen met dezelfde splinter in ons oog.

Ons staat vooral het zeer rigide karakter bij. De brede discretionaire ruimte waarover het OM beschikt, lijkt niet altijd gelukkig uit te werken. Het wordt mede ingekleurd door uitermate behoedzaam opereren van officieren, hetgeen vooral een pervers effect lijkt van het carrièrefnuikende effect van een vrijspraak. Een andere uitwerking hiervan is dat verdachten buitengewoon kwetsbaar worden: de druk zich te wentelen in berouw om zo vervolging toch af te wenden moet groot zijn, en het is de vraag wat onder die omstandigheden de praktische relevantie blijft van de onschuldpresumptie.

Wij beogen hiermee niet het Japanse strafrecht de maat te nemen. Daarvoor is onze kennismaking te beperkt geweest. Bovendien realiseren wij ons dat veel van de dingen die ons bevreemdden in het verlengde liggen van het Japanse leven van alledag: door het belang dat wordt toegekend aan het in de pas lopen en de meer collectivistische inrichting van de maatschappij. Maar naar ons idee functioneert discretionaire ruimte in het recht, en nu komen we terug bij de titel van deze bijdrage, ${ }^{15}$ vooral indien eerst door het recht een duidelijk, dwingend en beschermend kader wordt geboden waarbinnen vervolgens ruimte is voor improvisatie of maatwerk. Voor zover wij in Japan hebben gezien, leidt discretie hier vooral tot nieuwe dwingende structuren die buitenwettelijk zijn en mede daardoor niet gecomplementeerd worden door de bescherming van diezelfde wet. Dat is wat ons betreft niet echt iets om van te leren. 